\title{
Aeromedical retrieval to a university hospital emergency department in Scotland
}

S J Caldow, T R J Parke, C A Graham, P T Munro

Rural and island areas of Scotland benefit from the availability of the Scottish Ambulance Service paramedic staffed helicopter for transfers and primary scene responses. There are a small number of patients who require advanced airway management, invasive procedures, or critical care interventions to stabilise them before transport to definitive care. At present these additional skills are provided on an ad hoc basis by senior medical staff drawn from intensive care and emergency medicine at the receiving hospitals. Given the potential difficulties of training paramedics to use these infrequently used skills it may be preferable to establish a formalised system to access suitably trained medical staff. This case series illustrates the clinical challenges and potential benefits of such a service and discusses the practicalities involved.

A eromedical transport has a long history. During the first world war wounded soldiers were evacuated using military aircraft in France. ${ }^{1}$ In 1933 the Royal Flying Doctors Service was founded and began to operate in rural areas of Australia. The first reported use of a helicopter to retrieve a wounded casualty was in Burma in 1945 and in 1946 survivors from a crashed transatlantic flight in Newfoundland were rescued by army helicopter. During the Korean and Vietnam wars helicopters were used with increasing frequency, with medical staff being placed on ships to triage and give immediate treatment. ${ }^{2}$

Unsurprisingly, aeromedical transport was extended to the civilian population. The Scottish air ambulance service began using aircraft to transport patients from remote Scottish islands to the mainland in the 1960s. The first dedicated civilian helicopter evacuation service became operational in 1972 in Denver, Colorado. There are now in excess of 400 air transport services worldwide.

Scotland's geography provides a challenge to the emergency medical services with numerous populated islands along the west coast, extending to Shetland in the far north. Furthermore, population density is extremely low in the northern part of the mainland. Medical care is therefore constrained by issues of accessibility, facilities, and number of personnel. The beautiful and diverse countryside attracts many visitors and encourages many outdoor activities, from mountaineering to skiing. The inevitable resulting injuries add to the burden of agricultural, industrial, and road traffic accidents. Increasing emphasis on early resuscitation, combined with centralisation of medical services must be balanced against the need to provide appropriate access to health care regardless of location. Air transport is an important component of this.

The Scottish air ambulance service has incorporated an aeromedical service since 1989. Two paramedics and a pilot staff the helicopters. Air paramedic training includes intubation without drugs and needle thoracentesis but it does not include the use of anaesthetic drugs or formal thoracostomy. Studies of other rural helicopter services have suggested that these skills are required in only $1 \%-5 \%$ of flights ${ }^{3}$ (this study only included primary missions-that is, patients treated by a first responder flight crew including an anaesthesiologist).

The west of Scotland does benefit from a dedicated interintensive care transfer service but no formal arrangements exist for patients who require time critical transfers. A helipad servicing the west of Scotland is situated at the Southern General Hospital. All patients transferred by air are initially assessed by senior emergency department (ED) staff working within the hospital. On several occasions patients have required urgent medical intervention on arrival. Selected patients seem to benefit from an experienced physician with advanced airway and other critical care skills being part of the flight team. ${ }^{3}{ }^{4-8}$ Over the past two years, a senior physician from the ED or intensive care unit (ICU) has travelled with the paramedic crew on an ad hoc basis.

This paper aims to review the retrievals undertaken by medical staff from the ED or ICU of this hospital over the past two years and to discuss the potential and difficulties of setting up a critical care retrieval system.

\section{METHODS}

All requests for aeromedical retrievals are directed to the ED consultant or ICU consultant on call. These calls usually originate from rural general practitioners working in isolated community hospitals with limited diagnostic and therapeutic facilities. A joint decision is made between the duty ED and ICU consultants about the appropriateness of the proposed transfer and a retrieval team are designated from the available medical and nursing staff at the time.

Civilian ambulance helicopter, civilian fixed wing aircraft, or military helicopter transport is then arranged through the Scottish ambulance service airdesk in Dundee. The airdesk coordinates all air ambulance resources throughout Scotland and liaises with the military to access their aircraft resources when required. The team is either picked up directly from the helipad at the Southern General Hospital or is transported to the civilian ambulance helicopter base or Glasgow Airport (for fixed wing retrievals), both about three miles away.

The team is then transported to a helipad or airfield closest to the referring hospital and the patient is assessed, resuscitated, and stabilised before transfer back to the most appropriate hospital. Any doubts about airway maintenance lead to the establishment of a definitive airway and mechanical ventilation before transfer. Invasive arterial monitoring is often instituted given the difficulties of monitoring in flight. Nasogastric tubes, urinary catheters,

Abbreviations: ED, emergency department; ICU, intensive care unit 
Table 1 Retrievals during 2002-2003

\begin{tabular}{|c|c|c|c|c|c|c|c|c|c|c|}
\hline & Age & Sex & Reason for retrieval & GCS & Interventions & $\begin{array}{l}\text { Origin/distance (miles)/ } \\
\text { surface travel time } \\
\text { (h:min)* }^{*}\end{array}$ & Mode & $\begin{array}{l}\text { Flight time } \\
\text { (min) }\end{array}$ & $\begin{array}{l}\text { Transfer } \\
\text { time (h) }\end{array}$ & Outcome \\
\hline 1 & 54 & $M$ & $\begin{array}{l}\text { Airway obstruction, } \\
\text { seizures }\end{array}$ & E1 V2 M5 & RSI, ventilation & Mainland/90.8/3:47 & Civilian & 40 & 2.5 & Survived \\
\hline 2 & 64 & $M$ & $\begin{array}{l}\text { Head injury, facial } \\
\text { injury }\end{array}$ & E1 V2 M4 & $\begin{array}{l}\text { RSI, ventilation, } \\
\text { IBP }\end{array}$ & Island/29.4/1:29 & Civilian & 35 & 2.8 & Survived \\
\hline 3 & 78 & $\mathrm{~F}$ & Head injury & E4 V4 M6 & RSI, ventilation & Island/69.3/5:06 & Military & 40 & 2.5 & Survived \\
\hline 4 & 67 & $\mathrm{~F}$ & Ruptured oesophagus & E4 V5 M6 & $\begin{array}{l}\text { RSI, ventilation, } \\
\text { ICD }\end{array}$ & Mainland/84.5/2:19 & Civilian & 30 & 3 & Died \\
\hline 5 & 41 & $M$ & Meningitis, seizures & E1 V2 M3 & RSI, ventilation & Island/105.4/3:59 & Civilian & 45 & 3 & Died \\
\hline 6 & 46 & $M$ & Head injury, trismus & El V1 M1 & Ventilation, IBP & Mainland/24.5/1:09 & Military & 30 & 2.5 & Survived \\
\hline 7 & 32 & $M$ & Overdose baclofen & E1 V1 M2 & RSI, ventilation & Island/69.3/5:06 & Fixed wing & 90 & 12 & Survived \\
\hline 8 & 57 & $M$ & Farming accident & E4 V5 M6 & $I C D$, analgesia & Island/96/5:44 & Fixed wing & 60 & 3 & Survived \\
\hline 9 & 25 & $M$ & Maxillofacial trauma & E1 V2 M4 & Ventilation & Mainland/84.5/2:19 & Civilian & 40 & 2.5 & Unknown \\
\hline 10 & 65 & $\mathrm{~F}$ & Overdose barbiturates & El V1 Ml & $\begin{array}{l}\text { RSI, ventilation, } \\
\text { IBP }\end{array}$ & Mainland/24.5/1:09 & Civilian & 25 & 4 & Survived \\
\hline
\end{tabular}

and intercostal drains are all inserted and secured before transfer when required.

Sedation and paralysis are continued during transfer and flight. Patients are transferred back to the ED resuscitation room (most commonly at the Southern General Hospital) by ambulance from the airport or helipad for further assessment.

Patients were identified by a variety of means. The ED computerised admissions log was searched to identify all helicopter transfers and these were scrutinised to identify patients who were retrieved over the period January 2002 to December 2003. Senior staff from the ED and ICU were asked to identify any other retrieval in which they had been involved over the same time period. Once patients were identified, case notes were obtained and details of the retrieval were noted, including: age and sex of patient, clinical condition necessitating retrieval, Glasgow coma score on arrival, interventions required before transfer, problems during transfer, flight time (duration of return flight back to Glasgow), and duration of transfer (defined as time of call to time of arrival back at the Southern General Hospital).

\section{RESULTS}

Table 1 gives the results. Ten retrievals were undertaken over this two year period. One of these patients (patient 10) was retrieved to a local district hospital with an available ICU bed. There were no problems experienced during transfers and all patients remained haemodynamically stable throughout. Two patients ultimately died and seven survived; the outcome for one patient is unknown.

\section{DISCUSSION}

This study shows the interventions carried out to stabilise and transfer severely critically ill or injured patients from rural locations. The patients described in table 1 are a heterogeneous group but common factors include a reduced level of consciousness or agitation that would normally preclude air transport, a potentially at-risk airway with a requirement for rapid sequence intubation, or the need for tube thoracostomy. These skills are not available to Scottish ambulance service personnel or many rural general practitioners. All occurred in island or comparatively isolated rural locations with road travel times in excess of one hour. Distances in excess of 30 minutes land travel to definitive care are generally considered to support the use of air transport in preference to land ambulance..$^{45}$
The most common intervention required was securing a definitive airway by rapid sequence intubation in 7 of the 10 patients. In addition to securing the airway this represents the only safe way of transferring patients who may become restless or agitated during air transfer. Work in the USA, Germany, and Australia suggests that reduced mortality is related to the presence of a physician with critical care skills rather than purely as a result of reduced prehospital time from air transport alone. ${ }^{4-12}$ This suggests that rapid sequence intubation skills are required for any medical staff undertaking retrieval work. ${ }^{4-8}$ These skills are mandatory for staff working on the London HEMS team. ${ }^{13}$ At present the Scottish ambulance service helicopter paramedics and most rural general practitioners are not trained in these skills. The alternative of having paramedics undertake rapid sequence intubation is unlikely to be practical given the low frequency of such interventions.

A study of a medically staffed helicopter ambulance service in Norway found that the skills of an anaesthesiologist were not required in more than $95 \%$ of ambulance helicopter journeys, ${ }^{3}$ although this study only examined the primary response service and excluded inter-hospital transfers. On the basis of our experience, it seems that the possession of advanced airway skills and the ability to independently perform rapid sequence intubation is a mandatory skill for medical staff undertaking aeromedical retrieval work. Transfers such as these require experienced specialist input for continuing patient safety.

A common factor in our cases was direct discussion between the referring doctor and a senior clinician in emergency medicine or intensive care medicine at the receiving hospital. In some circumstances advice is sufficient but where this is not the case retrieval can be planned in terms of speed, personnel, and ultimate destination (often this discussion includes consultants from orthopaedics or general surgery or from other hospitals if that is where the most appropriate definitive care bed is located).

An obvious limitation of this study is that there may be selection bias for the cases included. At the time of the study detailed information on tasking, physiological parameters, and patient outcome for all air transfers were unavailable.

This case series illustrates that in only one Scottish region there are cases that require a level of advanced airway care, invasive procedures, or monitoring that would be difficult to provide from ambulance personnel alone. There are also difficulties in terms of skill maintenance because most 
patients transported from rural settings by helicopter do not require these skills.

The authors feel there is an opportunity to provide support to the Scottish ambulance service and rural hospitals in the form of senior medical staff with prehospital care and advanced airway skills to complement the HEMS service in selected cases. It is most probable that such staff would be drawn from consultants in emergency medicine and intensive care where critical care skills are used on a frequent basis.

\section{ACKNOWLEDGEMENTS}

We thank Mr Malcolm Gordon (consultant in accident and emergency medicine), Dr Magnus Garrioch (director of intensive care medicine), and Dr Drew Inglis (consultant in anaesthesia and intensive care medicine), all of the Southern General Hospital, for permission to report these cases and for helpful comments throughout

\section{Authors' affiliations}

S J Caldow, T R J Parke, C A Graham, P T Munro, Department of Accident and Emergency Medicine, Southern General Hospital, Glasgow, UK

Funding: none.

Conflicts of interest: none declared.

Correspondence to: Dr P T Munro, Department of Accident and Emergency Medicine, Southern General Hospital, Glasgow G51 4TF, UK; phil.munro@sgh.scot.nhs.uk
Accepted for publication 26 August 2004

\section{REFERENCES}

1 McNab A. Air medical transport: "hot air" and a French lesson. J Air Med Trans 1992;11:15-16.

2 Carter G. The evolution of air transport systems: a pictorial review. J Emerg Med 1986;6:499-504.

3 Neilsen RW, Ulvik A, Carlsen AW, et al. When is an anaesthesiologist needed in a helicopter emergency medical service in northern Norway? Acta Anaesthesiol Scand 2002;46:785-8.

4 Cameron PA. Helicopter transport: can physicians save lives? Aust N Z J Surg 1999:69:690-1.

5 Wills VL, Eno L, Walker C, et al. Use of an ambulance-based helicopter retrieval service. Aust N Z J Surg 2000;70:506-10.

6 Garner A, Rashford SL, Lee A, et al. Addition of physicians to paramedic helicopter services decreases blunt pediatric trauma mortality. Aust N Z J Surg 1999;69:697-701.

7 Lossius HM, Soreide E, Hotvedt R, et al. Prehospital advanced life support by specially trained physicians: is there a benefit in terms of life years gained? Acta Anaesthesiol Scand 2002;46:771-8.

8 Bartolacci RA, Munford BJ, Lee A, et al. Air medical scene response to blunt trauma: effect on early survival. M J Aust 1998;169:612-16.

9 Biewener A, Aschenbrenner U, Rammelt S, et al. Impact of helicopter transport and hospital level on mortality of polytrauma patients. J Trauma 2004;56:94-8.

10 Chappell VL, Mileski WJ, Wolf SE, et al. Impact of discontinuing a hospitalbased air ambulance service on trauma patient outcomes. J Trauma 2002;52:486-91.

11 Larson JT, Dietrich AM, Abdessalam SF, et al. Effective use of the air ambulance for pediatric trauma. J Trauma 2004;56:89-93.

12 Eckstein $M$, Jantos $T$, Kelly $N$, et al. Helicopter transport of pediatric trauma patients in an urban emergency medical services system: a critical analysis. $J$ Trauma 2002; 53:340-4

13 Mackay CA, Terris J, Coats TJ. Prehospital rapid sequence intubation by emergency physicians: is it safe? EMJ 2001;18:20-4. 